\title{
КОМАНДНАЯ ФОРМА ОРГАНИЗАЦИИ ТРУДА
}

\author{
В.Ф. ВОЛОДЬКО \\ д-р пед. наук, профессор
}

УО «Белорусский национальный технический университет»

\begin{abstract}
Аннотация
В статье рассматривается современная популярная форма организации труда командная. Показаны различия между профессиональными группами и командами, виды и характеристики команд, критерии их эффективности. Рассмотрены командные проиессы: развитие, сплочение, формирование командного мнения, межличностные трения.
\end{abstract} Проанализированы преимущества и недостатки командной организаџии труда.

Ключевые слова: команда, командные процессы, сплоченность, преимущества и недостатки командной работьл.

Abstract

The article is included the material about a popular form of professional activity command form.

The differences between professional groups and commands, types and specifications of commands, performance criteria are considered in the article. The author pays attention the principle command processes: development, forming of command point of view, interpersonal conflicts. The author also analyses the advantages and disadvantages of command professional activity.

Key words: command, command processes, advantages and disadvantages of command work.

\section{ВВЕДЕНИЕ}

Потребительский рынок в современных условиях глобализации создает высококонкурентную среду и необходимость гибкого реагирования на запросы покупателей, что приводит к поиску все новых форм организации труда. Наиболее значимым достижением в этом вопросе на рубеже веков стала командная форма организация труда. Команда - это несколько человек разной квалификации, объединенных для достижения совместной профессиональной цели.

Ряд теоретиков современного менеджмента столь высоко ставят значимость командного труда, что называют его революцией в организации производства и управления. Так, Ричард Дафт в своем фундаментальном труде «Менеджмент» пишет: «В корпоративной Америке происходит тихая революция: все больше и больше фирм переходят на командные принципы организации труда. Концепция командного труда являет новый облик организаций, ведь базисными элементами структуры становятся команды, а не отдельные индивиды» [1].

Высокая значимость командной работы была подтверждена и специальными 
исследованиями. В частности, в США было изучено 200 фирм из списка «500 лучших компаний», который регулярно появлялся на страницах журнала Fortune. Результаты опубликованы в статье под выразительным названием «Команда как главный герой» [2]. В ней убедительно доказываются преимущества командного труда перед суммарными усилиями индивидов, даже если они квалифицированны и трудолюбивы.

Организация труда в форме команды оказалась настолько эффективной, что начала вытеснять великое изобретение Генри Форда - конвейер массового производства. Так, в автомобильном гиганте Volvo отказались от сборочного конвейера, вместо этого весь цикл сборки автомобиля выполняют сборочные команды рабочих. В результате исчезла безликость - каждый собранный автомобиль имеет своих исполнителей.

Кстати, команды блестяще проявляют себя не только в вопросах организации производства. Команды менеджеров так же успешно решают сложнейшие управленческие задачи. Вокруг крупных, и даже средних руководителей формируются управленческие команды. Командный стиль руководства в теории и практике менеджмента признается как один из самых современных и эффективных.

\section{РЕЗУЛЬТАТЫ И ИХ ОБСУЖДЕНИЕ}

Команды являются специфическим социально-профессиональным образованием, главной особенностью которых является то, что отдельные люди вносят разный вклад в общее дело. Труд каждого не похож на работу коллег, а результатом является не механическая сумма, а своего рода мозаика, в которой отдельные элементы становятся значимыми только в целостном выражении.

Следует отметить, что ни производственная, ни учебная, ни неформальная группа командами не являются. Даже если цель у них единая либо схожая, она не является совместной. Рассмотрим различия между профессиональными группами и командами по основным показателям.

Таблица 1- Различия между группами и командами

\begin{tabular}{|l|l|l|}
\hline \multicolumn{1}{|c|}{ Показатель } & \multicolumn{1}{|c|}{ Группа } & \multicolumn{1}{c|}{ Команда } \\
\hline 1. Цель & Та же, что и у организации & Специфическая \\
\hline 2. На выходе & Продукты индивидуального труда & Продукты коллективного труда \\
\hline 3. Лидер & Назначенный & Ситуативный \\
\hline 4. Общение & «Необходимое и достаточное» & Неограниченное \\
\hline $\begin{array}{l}\text { 5. Измерение } \\
\text { эффективности }\end{array}$ & $\begin{array}{l}\text { Косвенное, в виде влияния на } \\
\text { общие показатели }\end{array}$ & $\begin{array}{l}\text { Непосредственное, в виде оценки } \\
\text { коллективной работы }\end{array}$ \\
\hline
\end{tabular}

Таким образом, концепция команды полагает, что все ее члены подчинены единой конкретной цели, создают общий продукт, несут коллективную ответственность. Лидерами команды на разных этапах ее работы могут выступать разные люди. Хотя последнее относится, 
конечно, к рабочим командам, а не управленческим.

Из сказанного следует, что команды по видам деятельности можно разделить на производственные и управленческие. Современный топ-менеджер должен обязательно иметь свою управленческую команду, которая сохраняется продолжительное время, сплачивается, приобретает совместный опыт деятельности, растет вместе с лидером.

Эффективность команды можно оценить по экономическим и психологическим индикаторам (показателям). Экономические индикаторы - это результаты совместной деятельности, то, насколько они успешны и значимы. Психологические индикаторы - это личная удовлетворенность каждого члена команды своей профессиональной жизнью (работой, общением, психологическим комфортом).

Можно создавать команды самых различных видов, это зависит от поставленных профессиональных задач, способов формирования команд, их внутреннего взаимодействия и специфики труда. Различают пять типов рабочих команд: горизонтальные, вертикальные, специализированные, самоуправляемые и виртуальные [3].

Горизонтальные команды - сформированы из специалистов примерно одного уровня, но разных отделов (специальностей). Обычно они решают межфункциональные задачи, поэтому их иногда называют межфункциональными командами. После выполнения поставленных задач члены команды могут возвратиться в свои отделы.

Вертикальные команды - включают менеджера и два-три иерархических слоя подчиненных. Такие команды, как правило, создаются для реализации определенных конкретных функций, одной или нескольких, поэтому их иногда называют функциональными.

Специализированные команды - создаются для разовых необычных заданий. Нередко такие задания являются очень важными и требующими уникальных творческих решений. Такие команды обычно выводятся за пределы действующих структур, и работают автономно. Изначально специализированная команда создается для решения одной конкретной задачи, однако, если в ходе работы команда сплотилась и показала высокую эффективность, она может быть сохранена и после решения задачи. В этом случае перед ней ставится новая задача.

Самоуправляемые команды - получившие высокую степень самостоятельности в выборе путей достижения цели. Нередко перед такой командой даже цель ставится весьма неопределенно, упор делается на творческий поиск членов команды. Самоуправляемой командой можно назвать знаменитые японские «кружки качества». Им не задается программа «качество чего улучшать»это может быть любой элемент как основной, так и вспомогательной деятельности. Члены кружка руководствуются как здравым смыслом, так и неожиданными идеями, творческими озарениями.

Виртуальные команды - совместная работа групп людей без личного контакта, через Интернет. Такие команды обычно возникают в организациях, структурные подразделения которых географически разбросаны на значительные расстояния. Это организации с сетевыми структурами, которые рассматриваются современным менеджментом как наиболее прогрессивные. 
Команда может быть описана двумя характеристиками: численность и роли участников.

Численность команды в 7 человек считается близкой к идеальной. Численность в 5-9

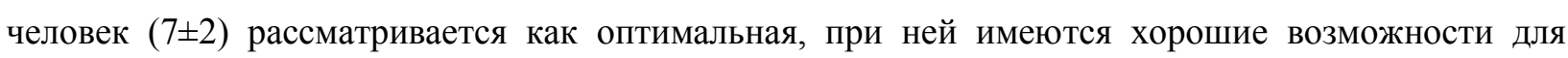
общения «каждого с каждым». При расхождении мнений сравнительно легко может быть достигнут «консенсус» (согласованная позиция).

Малые команды (2-4 человека) имеют больше согласия и неформальных отношений. Но их профессиональные возможности ограничены малым числом участников.

Большие команды (более 10 человек) располагают широким деловым потенциалом, но в них больше различий во мнениях, что может затруднить принятие решений. Внутри таких команд способны возникать неформальные микрогруппы, что может отрицательно сказаться на сплоченности команды.

Роли участников команд в образной форме обозначаются следующими понятиями: «спецы», «гармонители», «наблюдатели» и «смешанные» [4]. Отдельно стоит лидер.

«Спецы» - это наиболее квалифицированные и трудолюбивые члены команды, на них ложится «львиная доля» выполняемой командой работы. Лидер должен это понимать и постоянно учитывать в своей деятельности.

«Гармонители» - это люди, вносящие гармонию в межличностные отношения в команде, играющие важную роль в сплочении коллектива, создании в нем конструктивного психологического климата. И хотя они вносят меньший, чем «спецы», вклад собственно в работу, в конечном результате их роль не менее важна.

«Наблюдатели» - это члены команды, которые вносят малый вклад в общий совокупный продукт.

«Смешанные» - к ним относят тех, кого сложно квалифицировать по первым трем группам, они занимают в этом смысле некие серединные позиции, играют двойные роли.

В составе команды, особенно большой, избавиться от представителей какой-либо роли невозможно. При исключении кого-либо из команды, среди оставшихся прежние роли не сохраняются, происходит перераспределение, и снова появляются исполнители каждой роли.

Командная жизнь весьма динамична, даже если команда создана на относительно короткий срок, она все равно успевает пройти определенные этапы своего развития. В командах неизбежно происходят специфические внутренние процессы.

Командные процессы - это изменяющийся во времени характер межличностных отношений внутри команды. Выделяется четыре основных типа командных процессов: развитие, сплочение, формирование командного мнения, межличностные трения [5].

Развитие команды, в свою очередь, проходит три стадии: создание, «притирка», совместная работа.

Создание команды. Оно начинается с приказа о создании, в котором объявляется персональный состав команды и цель ее образования. Если члены вновь образованной команды ранее не знали друг друга, происходит процесс знакомства, если они были знакомы, сразу 
начинается внутренняя оценка друг друга в новом качестве. Это период некоторой неопределенности, «смятения», члены команды распределяются по социальному и профессиональному статусу, проявляются каждый в своей роли («спец», «гармонитель», «наблюдатель», «смешанный»). Команда при этом еще не является единым целым, происходит «присматривание» и «притирка» друг к другу.

«Притирка» в команде. На этой стадии проявляются и принимаются общие «правила игры», нормы поведения, складывается определенный консенсус по поводу распределения ролей, формируются первые межличностные взаимосвязи. Как правило, эта стадия проходит быстро.

Совместная работа. На данной стадии основное внимание команды направляется на решение профессиональных задач, на первый план выдвигаются «спецы». Между членами команды происходит активное деловое взаимодействие и общение.

В ходе работы и общения в команде может произойти сплочение. Но оно может и не произойти. Деловые отношения внутри команды перерастут в дружеские, либо нет, это во многом зависит от тех членов команды, которые оказались в роли «гармонителей». Если эти роли исполняются удачно, происходит сплочение команды, и наоборот.

После завершения работы (либо ее провала) команда расформировывается. Однако в случае, когда команда показала высокую эффективность и слаженность, умные руководители ее сохраняют, т.к. разрушать живой успешный производственный организм нецелесообразно. Таким образом, весьма желательным результатом командной динамики является сплоченность.

Командная сплоченность - это степень привлекательности команды для ее членов, уровень дружественности в межличностных отношениях. Участники сплоченных команд полностью привержены общей и своей личной работе, и получают от нее удовлетворение, они воспринимают командные успехи как свои собственные. Отношения внутри команды выходят за рамки деловых и превращаются в дружественные, члены команды с удовольствием встречаются в неформальной обстановке, поддерживают друг с другом доверительные отношения.

Командная сплоченность имеет следующие показатели (индикаторы): признание членами команды единства цели; высокая привлекательность команды для ее участников; активность личного неформального взаимодействия; гордость каждого за командные успехи. На сплоченность команды влияют три основных фактора: психологическая совместимость членов команды; характер совместной деятельности; внешняя среда.

Психологическая совместимость в команде. Она предполагает адекватность коллективной и личной оценки членов команды. Каждый ее участник имеет собственное суждение о своих человеческих и профессиональных качествах. Если оно в основном совпадает с оценкой коллектива, человек будет чувствовать себя комфортно, если же коллективная оценка сотрудника значительно ниже его самооценки, он будет постоянно внутренне переживать эту «несправедливость». К психологической совместимости относится еще и комфортность межличностного общения.

Характер совместной деятельности в команде. Как фактор влияния на сплоченность, 
совместная деятельность включает степень сложности и креативности работы. Если работа требует высокой квалификации и творчества, и члены команды соответствуют этим требованиям, то это может активно способствовать сплочению, и наоборот, рутинная и примитивная работа не способна объединять.

Внешняя среда. Она связана с конкурентностью и результативностью командной деятельности. Если между командами происходит конструктивное соперничество, внутренние командные связи от этого только укрепляются. Каждая команда стремится одержать верх в соревновании, при этом предмет конкуренции не важен. Внешняя конкуренция сплачивает команду, укрепляет командный дух и совместный успех, принадлежность и сопричастность.

Достоинства командной сплоченности можно разделить на профессиональные и психологические. Профессиональные достоинства достигаются за счет того, что каждый из участников вносит свою лепту в общее дело на уровне своих способностей, близком к максимальному. Каждый работает с полной отдачей по собственной воле, а не по принуждению, а общий результат органично складывается из индивидуальных. Психологические достоинства обеспечиваются хорошим моральным климатом, дружественной атмосферой, взаимопомощью и взаимоподдержкой. Решения в команде принимаются совместно (демократический стиль), все ставят коллективные интересы выше личных.

Формирование командного мнения. Этот командный процесс связан с согласованием профессиональных и человеческих ценностей, распределением ролей в команде. Участники принимают определенные правила поведения, происходит координация усилий в рамках совместной деятельности, разногласия разрешаются под углом зрения командных задач.

Командное мнение принимает общественные нормы - стандарты поведения. Как правило, эти нормы являются неформальными, то есть они нигде не зафиксированы, но они определяют рамки поведения и границы допустимого. Это обеспечивает успешную совместную жизнедеятельность команды.

Этапами формирования командного мнения могут выступать: критические события, прецеденты, внешний опыт, требования лидера.

Критические события. Они возникают на определенных «развилках» общественного мнения, когда появляются различные варианты, и тогда выбор в пользу того или иного может быть осуществлен под влиянием какого-либо события. Этот выбор и становится в дальнейшем нормой при возникновении подобных ситуаций.

Прецедент. Как этап формирования общественного мнения прецедент фиксируется тогда, когда впервые возникает какой-то вопрос. Принятое при этом решение впоследствии берется за основу при появлении сходных задач.

Внешний опыт. Он может быть привнесен в команду из иных коллективов. Носителями такого опыта обычно выступают те сотрудники, которые ранее участвовали в работе других успешных команд.

Требования лидера. Заявленные четко и однозначно, требования являются наиболее 
эффективными способами нормирования. Члены команды принимают это как данность, как элемент профессиональной установки и трудовой дисциплины.

Межличностные трения - это командные процессы, означающие неконструктивные взаимодействия между членами команды.

Надо понимать, что определенные трения неизбежны, однако дело в том, насколько они мешают работе и сплочению команды. Если они укладываются в определенные допустимые рамки, то это вполне терпимо. Следует лишь остерегаться, чтобы трения не выросли до неприемлемых размеров, не превратились в деструктивный конфликт.

Основными причинами трений могут быть: недостаток ресурсов; нечеткое разделение обязанностей в команде; кризис коммуникаций; несовместимость характеров; соперничество во власти и статусе; разногласия в путях достижения целей.

Как в удержании трений в рамках допустимого, так и в протекании остальных командных процессов исключительная роль принадлежит менеджеру - лидеру команды. Профессионально подготовленному менеджеру вполне по силам регулирование всех командных процессов на разных этапах их протекания. Это может быть обеспечено соответствующим знанием и постоянным вниманием менеджера к данным вопросам.

Командный труд, как следует из вышесказанного, весьма эффективная форма организации профессиональной деятельности. Однако не следует воспринимать его в качестве универсального средства. Выбирая форму организации труда, менеджерам надо взвесить все «за» и «против». Для этого надо знать преимущества и недостатки работы в командах. Рассмотрим основные из них.

Преимущества работы в командах.

В теории управления выделяется четыре преимущества командного труда: повышение эффективности; личное удовлетворение; расширение знаний и умений; организационная гибкость [6].

Повышение эффективности. Результат совместной деятельности всегда выше, чем сумма индивидуальных усилий. Это вытекает из основного закона гештальт-психологии: «Организованное целое превышает сумму своих составляющих». Объединение сотрудников в команду, если ее идея интересна и привлекательна, способствует высвобождению огромной внутренней энергии и творческого потенциала людей. Нередко именно переход к командным формам организации труда становится главным фактором повышения эффективности работы предприятия.

Личное удовлетворение. Как доказал Абрахам Маслоу, у каждого человека имеется потребность в уважении, привязанности, доверительных отношениях. Людям хочется признания своего профессионального мастерства и человеческих достоинств. Работа в команде способствует удовлетворению данной потребности, она позволяет реализовать себя, осознать собственные способности, получить удовлетворение от своей профессиональной деятельности.

Расширение знаний и умений. В рамках команды активно используется потенциал наиболее подготовленных сотрудников. Команда естественным образом делегирует им полномочия по 
выполнению наиболее сложных заданий, хотя это вовсе не сопровождается послаблением для остальных членов команды. Они активно усваивают знания и опыт коллег, учатся на конкретной деятельности. Такие уроки, как показывает практика, оказываются очень эффективными.

Организационная гибкость. В рамках команды естественным образом осуществляется взаимозаменяемость, подстраховка друг друга. Задания изначально распределяются с учетом желаний, способностей, квалификации, занятости членов команды. При необходимости задания могут быть реорганизованы, разбиты на части и поручены разным сотрудникам, И наоборот, возможно укрупнение схожих заданий в единое целое. Возможно также перераспределение, команда может гибко реагировать на изменяющиеся условия работы и возникающие новые задачи.

Недостатки командной работы.

Даже самое положительное явление не лишено определенных недостатков, и эта закономерность относится также к работе в командах. Рассмотрим три наиболее частых недостатка командной работы: перестройка структуры власти; «безбилетники»; затраты на координацию [7].

Перестройка структуры власти. Создание команды приводит к тому, что сотрудники выводятся из сложившейся системы властных отношений, и помещаются в другую. Это затрагивает интересы многих из них, и особенно менеджеров. Нередко создание команды приводит к уменьшению потребностей в менеджерах первичных уровней (фёст-менеджеры). При создании команды менеджерам часто приходится делиться частью своих полномочий, либо отдать из своего подчинения отдельных сотрудников. Многие менеджеры воспринимают подобные факты как понижение своего статуса.

Кроме того, в условиях новой трудовой структуры неизбежна «притирка». Официальные полномочия и неформальное влияние создают новый властный механизм, на становление которого требуется некоторое время.

«Безбилетники». Выше, при рассмотрении ролей участников команд, выделена категория «наблюдателей», т.е. сотрудников, которые вносят сравнительно малый вклад в общее дело. Этот вклад может быть настолько мал, что подобных «вкладчиков» вполне уместно назвать «безбилетниками», или «зайцами», которые «едут в общей повозке» команды, но при этом не платят. Экономические и психологические преимущества членов команды распространяются на всех, а зарабатывают их не все, во всяком случае, далеко не в равной степени. Особенно актуально указанное положение в больших командах, т.к. социальное и профессиональное отлынивание в них имеет большие возможности. Так, психологами установлено, что когда за веревку тянет один человек, он прилагает гораздо больше усилий, чем в составе группы.

Затраты на координацию. Создание команды всегда требует какое-то время на организационные усилия, а затем команда должна пройти этап становления, «притирки» участников друг к другу. Новые задания требуют координации усилий членов команды по обеспечению совместной деятельности. Распределение общей задачи по частям, подготовка к 
процессу труда занимает какое-то время. На фоне сложившихся в предыдущей трудовой структуре обязанностей новая команда оказывается по времени в определенном смысле затратной, особенно это заметно на первом этапе.

Принимая решение о создании команды, не надо гнаться за модной формой организации труда. Надо взвесить все возможные преимущества и недостатки с учетом предполагаемой командной задачи. Однако профессиональная жизнь успешных компаний в подавляющем большинстве ситуаций подтверждает эффективность работы в командах. Причем относится это как к производственной, так и к управленческой деятельности.

\section{ВЫВОДЫ}

1. Наиболее значимым достижением на рубеже веков в условиях высоко-конкурентной среды и необходимости гибкого реагирования на запросы покупателей стала командная форма организация труда. Командой называют несколько человек разной квалификации, объединенных для достижения совместной профессиональной цели. Процесс массового перехода на командные принципы организации на Западе получил название «тихой революции». Команды могут быть рабочими и управленческими.

2. В зависимости от поставленных профессиональных задач, способов формирования команд, их внутреннего взаимодействия и специфики труда, различают пять типов рабочих команд: горизонтальные, вертикальные, специализированные, самоуправляемые и виртуальные. Эффективность команды можно оценить по экономическим результатам и психологическим показателям - личной удовлетворенности участников своей профессиональной жизнью. Участники команд могут выступать в разных ролях, которые в образной форме называются: «спецы», «гармонители», «наблюдатели», «смешанные», лидер.

3. Командная жизнь очень динамична, в ней постоянно происходят специфические внутренние процессы, то есть изменяющиеся во времени межличностные отношения. Основными командными процессами являются: развитие, сплочение, формирование командного мнения, межличностные трения. Особую значимость в успешной деятельности команды имеет ее сплоченность, то есть дружественность в межличностных отношениях, высокая привлекательность команды для ее участников, гордость каждого за командные успехи.

4. Командная организация труда имеет свои преимущества и недостатки. Выделяется четыре преимущества: повышение эффективности; личное удовлетворение; расширение знаний и умений; организационная гибкость. К недостаткам командной работы относятся: перестройка структуры власти; «безбилетники»; затраты на координацию. Принимая решение о создании команды, надо взвесить все возможные преимущества и недостатки с учетом предполагаемой задачи и состава команды. 


\section{ЛИТЕРАТУРА:}

1. Дафт, Р. Менеджмент / Р. Дафт; пер. с англ. - СПб.: Питер, 2002. - С. 560.

2. Treining in the 1990s // The Wall Street Journal. - 1990. - B1. - March 1. - P. 14.

3. Володько, В.Ф. Основы менеджмента / В.Ф. Володько; 3-е изд. - Минск: АiВ, 2010. C.162.

4. Володько, В.Ф. Основы менеджмента / В.Ф. Володько; 3-е изд. - Минск: АiВ, 2010. - С. 164.

5. Володько, В.Ф. Психология управления. В 2-х томах / Том I: Психология объекта и субъекта управления / В.Ф. Володько. - Минск: Технич. лит-ра, 2012. - С. 344.

6. Володько, В.Ф. Психология управления. В 2-х томах / Том I: Психология объекта и субъекта управления / В.Ф. Володько. - Минск: Технич. лит-ра, 2012. - С. 347.

7. Володько, В.Ф. Психология управления. В 2-х томах / Том I: Психология объекта и субъекта управления / В.Ф. Володько. - Минск: Технич. лит-ра, 2012. - С. 348. 